\title{
Attainable Region Approach in Analyzing the Breakage Behavior of a Bed of Olivine Sand Particles: Optimizing Impact Energy and Particle Size
}

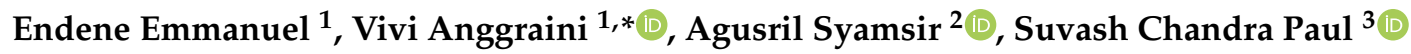 \\ and Afshin Asadi 4 (D) \\ 1 Civil Engineering Discipline, School of Engineering, Monash University Malaysia, Jalan Lagoon Selatan \\ Bandar Sunway 47500, Selangor, Malaysia; emmanuel.endeneche@monash.edu \\ 2 Institute of Energy Infrastructure, Universiti Tenaga Nasional, Jalan IKRAM-UNITEN, Kajang 43000, \\ Selangor, Malaysia; agusril@uniten.edu.my \\ 3 Department of Civil Engineering, International University of Business Agriculture and Technology, \\ Dhaka 1230, Bangladesh; suvashpl@iubat.edu \\ 4 Civil Engineering Discipline, International College of Auckland, 520 Queen Street, Auckland 1010, \\ New Zealand; afshin.asadi@ica.ac.nz \\ * Correspondence: vivi.anggraini@monash.edu
}

Received: 30 October 2020; Accepted: 5 December 2020; Published: 7 December 2020

\begin{abstract}
In this study, we investigated the breakage behavior of a bed of olivine sand particles using a drop-weight impact test, with drop weights of various shapes (oval, cube, and sphere). An Attainable Region (AR) technique, which is a model-free and equipment-independent technique, was then applied to optimize the impact energy during the breakage process and also to get particles in defined particle size classes. The findings revealed that the different drop weights produce products within the three different particle size classes (feed, intermediate, and fine). A higher mass fraction of materials in the fine-sized class $(-75 \mu \mathrm{m})$ was obtained when the spherical drop weight was used relative to the cubic and oval drop weights. The drop height was found to have a significant influence on the breakage process. The AR technique proved to be a practical approach for optimizing impact energy and particle size during the breakage of a bed of olivine particles, with potential application in sustainable soil stabilization projects.
\end{abstract}

Keywords: attainable region; optimization; olivine; drop-weight; particle size; impact energy

\section{Introduction}

In recent years, the use of sustainable, cost-effective, and efficient materials for a wide range of geotechnical and geo-environmental engineering applications, including soil stabilization, has received increased attention. Reactive minerals constitute one such natural materials commonly used for soil stabilization projects. To that effect, a good number of researchers have made an effort to report the application of reactive minerals, such as olivine, wollastonite, magnesia, and serpentine, as improvers for weak soils [1-5]. Olivine has been demonstrated to be the most promising candidates, with valuable environmental assets among the varieties mentioned above [6-8].

Despite such positive findings in the use of olivine, an important factor to be considered in the widespread application of olivine in soil stabilization is olivine particle size, since the reactivity between olivine and soil largely depends on its particle size. O'Connor et al. [9] demonstrated that particle size plays an important role in reaction kinetics, since most mineral dissolution reactions are controlled at the surface. Therefore, in order to attain an adequate reactivity between the olivine and 
the soil, the olivine particle size must be reduced (i.e., increase the specific surface area) before adding it to the soil.

Comminution, a process of particle size reduction by an applied force, is vital in making products spanning from paint pigments to drug crystals for pharmaceutical tablets, to asphalt for road pavement, and to additives for soil improvements [10]. It is estimated that over $4 \%$ of the world's energy is consumed by comminution industries [11]. Khumalo et al. [12] estimated that energy costs account for $\sim 50 \%$ of mineral processing plants. The major setback in comminution is how to optimize the input energy in the breakage process, where it has been demonstrated that only a trivial percentage $(\sim 1.5 \%)$ of the total input energy accounts for the breaking, while the rest is consumed by the equipment and lost to contacts that do not result in breakage [13]. Consequently, any small improvement in energy efficiency provides an opportunity to increase profitability since energy is often the principal operating cost in the breakage process.

Several researchers have made efforts to study the comminution process in the domain of mineral processing with the aim of establishing optimal operating conditions. The breakage kinetics [14-16], load behavior $[17,18]$, and mill power $[19,20]$ have been studied in terms of mill speed, ball size, and interstitial filling [21]. However, little to no study has been conducted on extending the comminution process in the domain of soil stabilization and reinforcement to establish optimum operating parameters. Hence, obtaining the optimal particle size of sustainable soil additives with the potential of reducing energy consumption and operational costs while minimizing the crushing inefficiency has been a common problem encountered in recent years.

Thus, any research efforts with the potential of reducing energy use and costs of operation while maximizing the crushing efficiency and optimizing particle size are most welcome. In the comminution process, optimization of operational parameters has required the use of a classifier or screen to separate the coarsely sized material and return it to the crusher for re-crushing. The choice of the "appropriate" classifier is based on the assumption that the best size specification required by the succeeding concentration processes is met. The specification of the required size has traditionally been achieved based on experience [22]. This technique, which includes no methodical way of crushing the particles, often leads to excessive energy consumption and operational costs. This downside can be eliminated by employing a technique that optimizes energy use in the breakage process.

Various methods have been employed in comminution in order to optimize energy use in the size reduction process [23-26]. The Attainable Region (AR) technique is one such method commonly employed, and is gaining wide attention; nonetheless, the full potential of the technique is still to be exploited. In this article, we extended the application of the AR technique to optimize impact energy and particle size on the breakage behavior of a bed of olivine sand particles using a drop-weight impact test. The AR technique has never been applied for grinding additives for soil stabilization projects. Hence, the findings from this work would make an important contribution to the study of olivine comminution with a view towards sustainable soil stabilization. However, the authors would like to indicate that this study is not intended to establish standard operating conditions for laboratory drop-weight impact tests on a bed of olivine sand particles, but rather to show how the technique can be employed and to highlight areas for further improvement. The significance of this study is geared towards minimizing the inefficiency of the grinding process as an optimized impact energy, and suitable product size would be achieved for subsequent application in soil stabilization projects.

\subsection{Impact Breakage}

The quantity of energy consumed during a comminution process in ball mills has in recent decades been, and remains, a topic of extensive research, with several scholars demonstrating that size reduction is the most energy-intensive and inefficient operation in any comminution process [27]. Impact, compression, and abrasion constitute the main grinding mechanisms that occur in the mill during comminution [28]. According to Lynch et al. [29], the tumbling action inside a mill can be simulated outside a mill via impact techniques such as the drop weight test. Tavares and King [30] described the drop weight test as a straightforward technique used to examine the breakage behavior 
of a material and has the advantages of simplicity in operation, flexibility, and the possibility of particle bed testing, among others.

Several scholars have examined the impact breakage process to determine the optimum impact route of an ore. They concluded by indicating that the specific and input energies of particles are important fundamental properties [31-33]. The minimum input energy $\left(E_{b}\right)$ required for the breakage of a particle can be calculated using Equation (1).

$$
\mathrm{E}_{\mathrm{b}}=\mathrm{m}_{\mathrm{b}} \mathrm{gh}
$$

where $\mathrm{m}_{\mathrm{b}}=$ mass of the drop weight $(\mathrm{kg}) ; \mathrm{g}=$ acceleration due to gravity $\left(\mathrm{m} / \mathrm{s}^{2}\right)$, and $\mathrm{h}=$ drop height $(\mathrm{m})$.

The total impact energy $\left(\mathrm{E}_{\mathrm{T}}\right)$ and the specific energy (Es) can be obtained using Equations (2) and (3), respectively.

$$
\begin{aligned}
& \mathrm{E}_{\mathrm{T}}=\mathrm{NE}_{\mathrm{b}} \\
& \mathrm{E}_{\mathrm{s}}=\frac{\mathrm{E}_{\mathrm{T}}}{\mathrm{m}_{\mathrm{p}}}
\end{aligned}
$$

where $\mathrm{N}=$ number of drops/impacts; $\mathrm{m}_{\mathrm{p}}=$ mass of the particle bed $(\mathrm{g})$.

Hlabangana et al. [28] and Danha et al. [11] used the above equations to demonstrate that the Es of breakage can be altered by varying the mass of the drop weight, the number of drops, particle bed mass, and drop height.

\subsection{The Attainable Region Concept}

As a mining or geotechnical engineer, envisage you are presented with a comminution task with known states (feed material, drop heights, drop weights, and number of drops) and challenged to crush the feed material to an optimal particle size while determining the optimum operating conditions required in achieving the optimal particle size. Would you start crushing the feed material by running a series of drop weight impact tests? And if so, how would you know the best operating conditions (adequate drop height, required number of drops, and suitable drop weight) in achieving the optimal particle size? That is the question the concept of attainable region addresses, and thus the issue of global optimality in the comminution process.

The AR is a model-free and equipment-independent optimization method that integrates elements of geometry to better comprehend the breakage process [12]. Abunde et al. [34] defined AR as the set of all possible outputs for a given system that can be attained by employing the basic processes occurring within the system that satisfy all the constraints placed by the system. From a geometrical viewpoint, the AR represents the area bounded by the convex envelope for the set of points attainable by the basic processes occurring in the system. Upon determination of the AR, the limits of achievability by the system for the given feed point are known, and the boundary of the AR can then be used to provide solutions to various optimization problems connected to the system [35]. The subsequent steps are necessary in order to apply the AR technique [34]:

- Step one: choose the basic processes occurring in the system (e.g., comminution, flotation, leaching, reaction, mixing, etc.).

- Step two: choose the state variables which characterize the output state of the system.

- Step three: construction of a candidate AR.

- Step four: interpret the AR boundary.

- Step five: locate a point in the AR plot where the process is optimized.

A considerable amount of study has been conducted on the use of the AR technique in various fields of science and engineering, such as batch reactors [36], batch distillation [37], reaction engineering [38], biotechnology [39], distillation [40], etc. Similarly, in mineral processing, various researchers have employed the technique to optimize factors such as residence time [41], particle breakage [42], and ball 
size distribution [43]. However, the AR technique is yet to be applied in the optimization of olivine sand comminution. It is our hope that, from this research, an attempt will be made to arrive at an optimized solution for sustainable soil stabilization.

\section{Materials and Methods}

\subsection{Materials}

\subsubsection{Olivine}

The olivine used in this study was procured from Maha Chemical, Sdn Bhd Selangor, Malaysia. The olivine had a specific gravity of 2.99 , and the $\mathrm{pH}$ was 8.91 . The physico-chemical and mineralogical properties of the olivine are given elsewhere [8].

\subsubsection{Sample Preparation}

The procured olivine was first sorted by hand picking to remove any foreign particles. Later, the olivine was sorted by particle size, where batches of approximately $1 \mathrm{~kg}$ of olivine were screened one after another using a stack of sieves for about $5 \mathrm{~min}$ to obtain a maximum particle size of $-2000 \mu \mathrm{m}$. Finally, the different masses obtained, which were ready for testing, were split using a cone and quartering technique to constitute about $30 \mathrm{~g}$ representative feed olivine samples $(-2000+420 \mu \mathrm{m})$. After this last step in the preparation, the feed samples were ready for testing. The samples were kept in plastic bags and stored in the laboratory.

Table 1 depicts the class specifications used in this study. Each industry is bound to have a different target product fineness. For example, the pharmaceutical industry will opt to produce a finer material $(-150+100 \mu \mathrm{m})$ of active ingredient in a drug in order to increase its bioactivity [28]. Similarly, the cement industry would go finer $(-50+2 \mu \mathrm{m})$ in the production of clinker so as to obtain easy burning by using low heats of calcination thereby reducing production costs [28]. In line with that, we would like to indicate that there are no widely accepted ideal comminution product size distribution for olivine particles for soil stabilization projects. Nonetheless, since the reactivity between olivine and the soil increases with a decrease in olivine particle size, we propose that a fine size class of $-75 \mu \mathrm{m}$ could be an ideal comminution olivine product size distribution for use in sustainable soil stabilization projects. In this regard, it is important to note that the size classes for the M1 and M2 were randomly chosen for the sake of demonstration. Hence, any other size class could have been used. The class sizes are not intended to be used as ideal operating class sizes for all impact drop weight test.

Table 1. Class size specification used for the application of the AR analysis.

\begin{tabular}{cccc}
\hline Class Size $\left(\mathbf{M}_{\mathbf{i}}\right)$ & Description & Upper Limit $(\mu \mathrm{m})$ & Lower Limit $(\mu \mathrm{m})$ \\
\hline $1(\mathrm{M} 1)$ & Feed & -2000 & +420 \\
$2(\mathrm{M} 2)$ & Intermediat & -420 & +75 \\
$3(\mathrm{M} 3)$ & Fine & -75 & to pan \\
\hline
\end{tabular}

\subsubsection{Drop Weight}

Three different drop weight shapes, viz; spherical, oval (ellipsoidal), and cubic, were employed in this study. To ensure that the effect of breakage was purely a function of shape; all the three weights were of the same mass (see Table 2). The dimensions of the various drop weights are given in Table 3.

Table 2. Drop weight test conditions.

\begin{tabular}{cc}
\hline Variable & Parameters \\
\hline Drop Height $(\mathrm{h})$ & $0.5,1.0,1.5,2.0,2.5 \mathrm{~m}$ \\
Drop weight $(\mathrm{w})$ & $0.395,0.420,0.441 \mathrm{~kg}$ \\
Particle bed mass $\left(\mathrm{m}_{\mathrm{p}}\right)$ & $10,20,30,40,50 \mathrm{~g}$ \\
Number of drops $(\mathrm{N})$ & $100,200,300,400,500$ drops \\
\hline
\end{tabular}


Table 3. Dimensions of the drop weights.

\begin{tabular}{cccc}
\hline Drop Weights & Width/Minor Axis & Height/Major Axis & Aspect Ratio \\
\hline Sphere & - & $4.7 \mathrm{~cm}$ & $1: 1$ \\
Cube & $4.8 \mathrm{~cm}$ & $4.8 \mathrm{~cm}$ & $1: 1$ \\
Oval & $2.8 \mathrm{~cm}$ & $4.6 \mathrm{~cm}$ & $0.61: 1$ \\
\hline
\end{tabular}

\subsection{Methods}

The drop weight test was conducted on beds of olivine sand particles using the experimental setup shown in Figure 1, which consists of an iron block anvil (as a crushing surface) and a polycarbonate tubing (as a hollow cylinder to allow passage of the drop weight and to restrict the breakage area) with an inside diameter of $5.3 \mathrm{~cm}$. The feed material to be tested was manually poured via the tube. The cone and quartering technique was used to reduce the sample size to the required amount so as to make a bed of olivine particles. The advantage of coning and quartering is that it reduces the variation (the standard deviation) among the samples, thereby reducing the number of samples that must be sorted. This approach is consistent with those reported by $[11,28]$. After a series of five impacts, the crushed and uncrushed particle fragments from the anvil were removed and poured into a tray to mix the particles before subjecting them to the next series of five impacts (or more breakage). This process continued until the required number of impacts was reached. The different drop heights $(\mathrm{h})$, drop weights $(\mathrm{w})$, number of drops $(\mathrm{N})$, and particle bed mass $\left(\mathrm{m}_{\mathrm{p}}\right)$ employed in the current study are summarized in Table 2 . The dimensions of the bed were approximately $1.5 \mathrm{~cm}$ height by $1 \mathrm{~cm}$ breadth by $1.3 \mathrm{~cm}$ depth. The bed height was maintained by making sure that all the material was retained within the polycarbonate tube. For the cube and oval drop weight shapes, the initial orientations of the drop weights were maintained throughout the testing. Nevertheless, the same orientation may not be guarantee upon impact. This approach was, however, used to lessen the influence of impact geometry on the final grading of the particles. In the setup, the drop weight was raised to the required height and was then released to fall freely onto the bed of olivine particles positioned in the center of the anvil. This approach was to minimize the loss of the actual momentum of the drop weight upon impact. Nevertheless, the authors would like to acknowledge that the same momentum of the drop weight upon impact may not be guarantee throughout the testing. The PSD of the product from the breakage process were then analyzed using the sieve analyses.

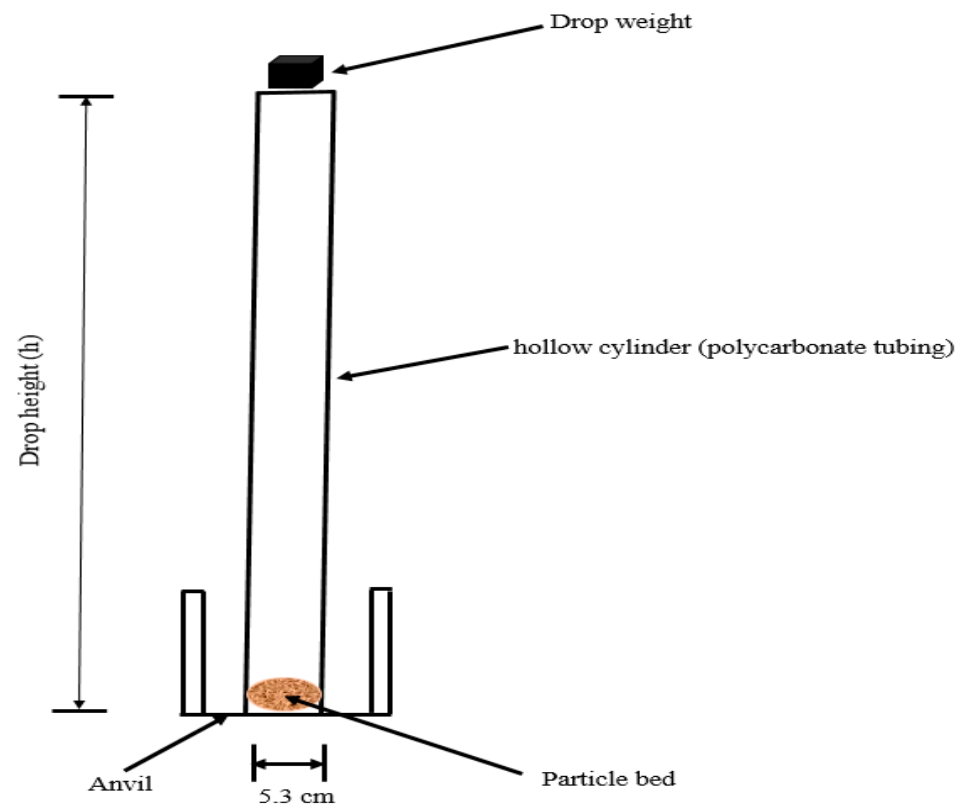

Figure 1. Schematic experimental setup of the drop weight apparatus. 


\section{Results and Discussion}

Figure 2 presents the AR plot of mass fraction of material in the feed size class (M1) against the drop heights $(0.5,1,1.5,2$, and $2.5 \mathrm{~m})$ for different drop shapes (cube, oval, and sphere) and drop weights $(0.395,0.420$, and $0.441 \mathrm{~kg})$. In this plot, the drop height, drop shapes and drop weights are the manipulated variables, while the mass fraction of the M1 is the process or output variable. In line with the AR optimization technique, the area bounded by the curve, Y-axis, and X-axis depicts the achievable region within which the different combinations of drop height and mass fraction of the M1 lie. Looking at Figure 2, it is apparent that as the drop height increases from 0.5 to $2.5 \mathrm{~m}$, the mass of material remaining in the M1 after the breakage process reduces gradually. The same breakage profile is consistent for all the three drop weight shapes, with the difference being the relative amounts of the material being broken from or remaining in the M1.

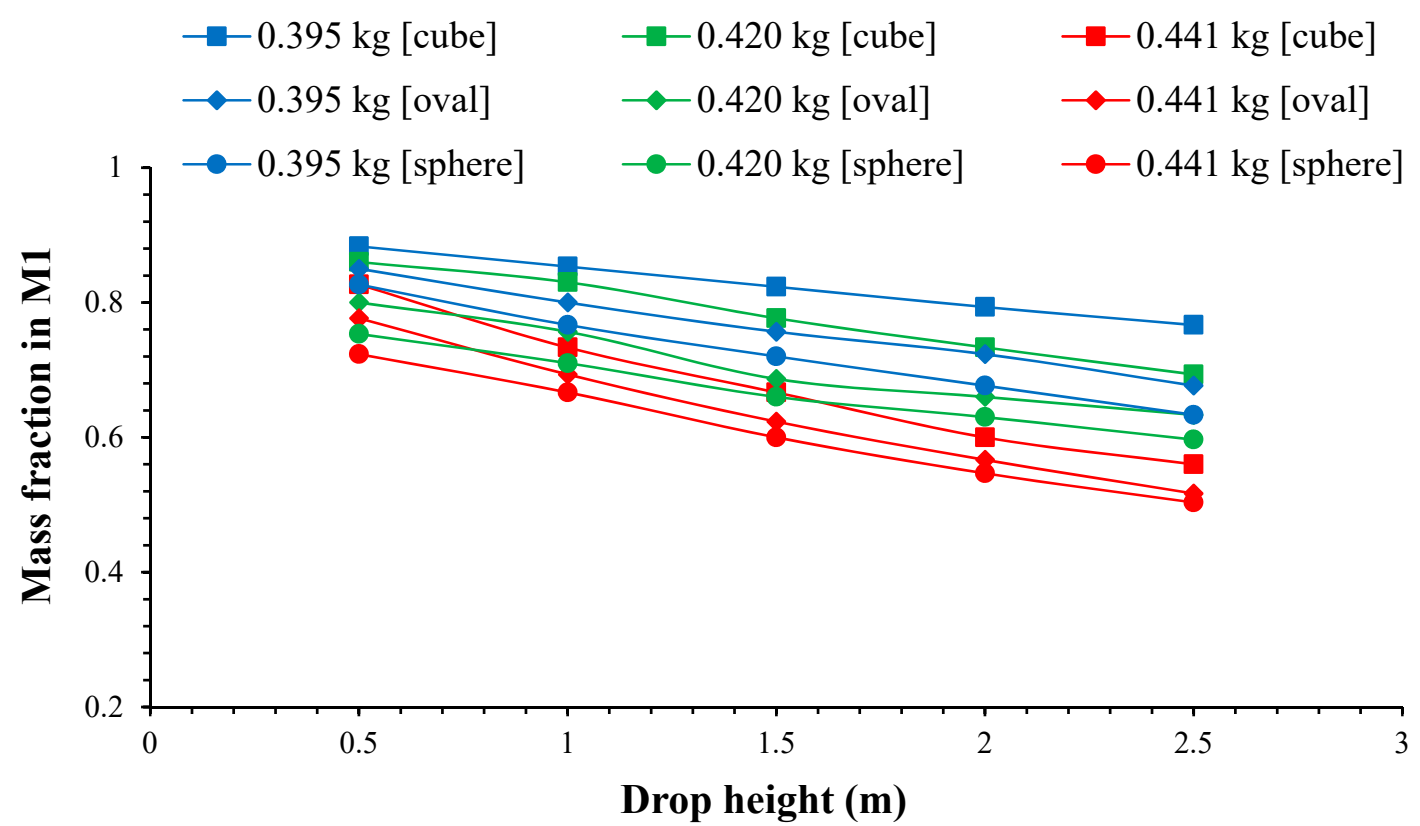

Figure 2. Mass fraction of material in the M1 vs. the drop height for different drop shapes and weights (bed mass $=30 \mathrm{~g}$, number of drops $=100$ ).

The main reason for the reduction in the mass fraction of materials in the M1 with increasing drop height is due to the impact forces. At a higher drop height, the impact forces are greater relative to shorter drop heights, thus facilitating the breakage of the material. Figure 2 also shows that the spherical drop weight has a higher reduction rate of the M1 relative to the oval and cubic drop weight shapes. Hence, implying that the spherical drop weight will provide the highest amount of materials in the M2 at a faster rate relative to the other drop weight shapes. Hlabangana et al. [28] indicated that different grinding drop weight shapes have different surface areas and impact orientation owing to their geometry. Figure 2 further shows that the $0.441 \mathrm{~kg}$ drop weight provides a maximum rate of breakage for all drop weight shapes relative to the $0.395 \mathrm{~kg}$ and $0.420 \mathrm{~kg}$ drop weights.

Figure 3 depicts a typical AR plot of the mass fraction of material in the intermediate sized class (M2) against the drop heights for different drop shapes and drop weights. As seen from Figure 3, the mass fraction of material in the M2 gradually increases to a maximum as more mass is being broken from the M1 to M2. A further increase in the drop height leads to a reduction of the mass fraction of material in the M2, as mass begins to break directly into the fine size class (M3). It is evident from Figure 3 that there is a maximum height for which the drop weight must be release in order to optimize the desired product. In line with the above view, if we aim to have products with a maximum amount 
of material in the M2, we can achieve this by releasing a $0.420 \mathrm{~kg}$ or $0.441 \mathrm{~kg}$ spherical drop weights from heights of $1.5 \mathrm{~m}$ and $1 \mathrm{~m}$, respectively.

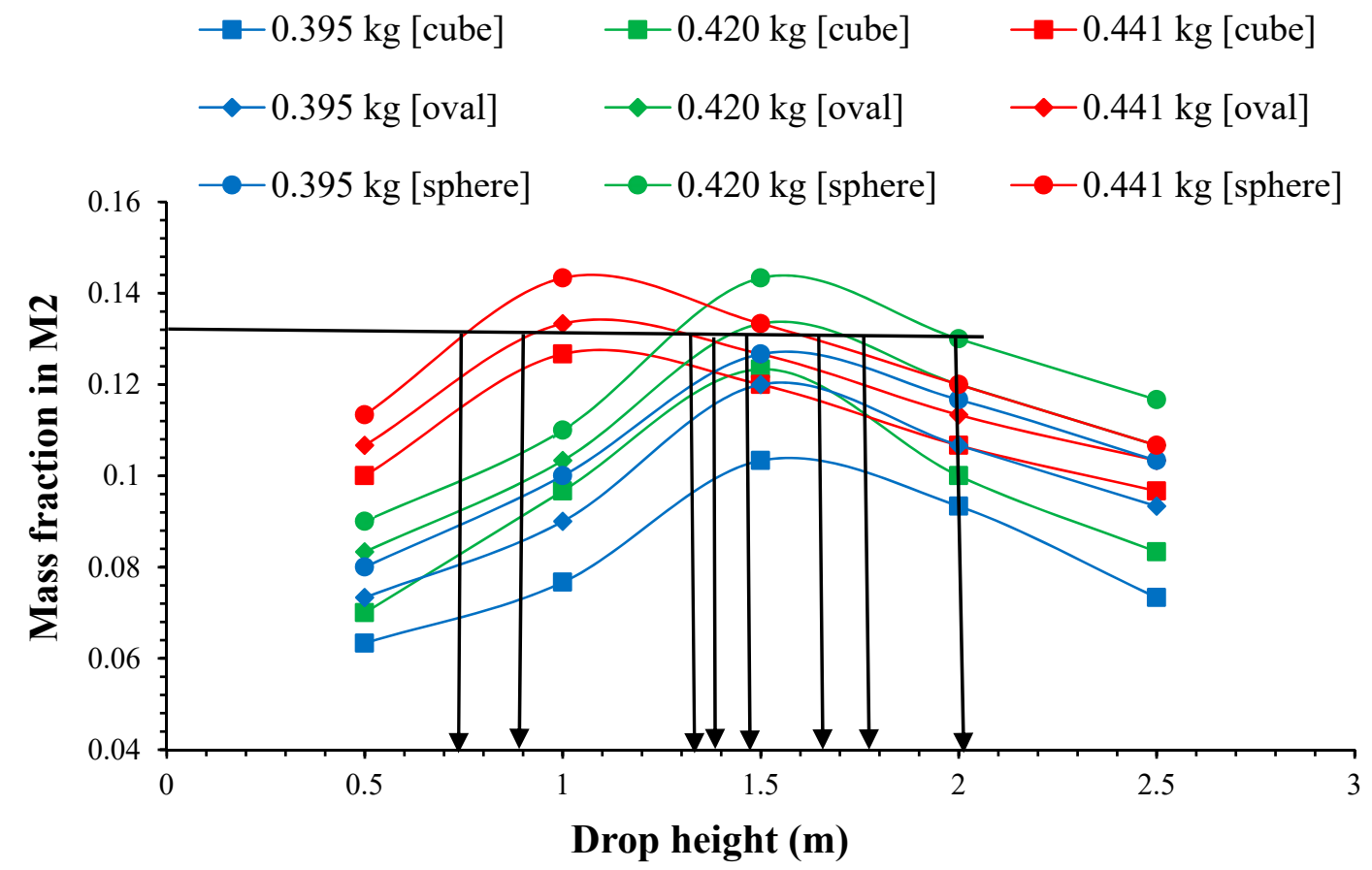

Figure 3. Mass fraction of material in the M2 vs. the drop height for different drop shapes and weights (bed mass $=30 \mathrm{~g}$, number of drops $=100$ ).

Similarly, if our aim is to achieve a mass fraction of 0.132 of the M2 material in the product, we can accomplish this by releasing the $0.441 \mathrm{~kg}$ spherical drop weight from either a height of $0.75 \mathrm{~m}$ or $1.62 \mathrm{~m}$; or by dropping the $0.420 \mathrm{~kg}$ spherical drop weight from either a height of $1.3 \mathrm{~m}$ or $2 \mathrm{~m}$; or by dropping the $0.441 \mathrm{~kg}$ oval drop weight from either a height of $0.9 \mathrm{~m}$ or $1.35 \mathrm{~m}$; or by dropping the $0.420 \mathrm{~kg}$ oval drop weight from either a height of $1.43 \mathrm{~m}$ or $1.74 \mathrm{~m}$. The difference in the various drop height options lies in the relative amounts of the M1 and M3 materials associated with accomplishing the desired aim. For energy optimization purposes, the AR plot assists the engineer in deciding to drop from a lower height (e.g., dropping from $0.75 \mathrm{~m}$ rather than $1.62 \mathrm{~m}$ ) in order to accomplish the same desired aim while reducing the operational costs such as fabricating longer hollow cylinders.

Interestingly, the plot (Figure 3 ) is somewhat counterintuitive, since we were expecting less of the M2 material for the heavier drop weights $(0.420 \mathrm{~kg}$ and $0.441 \mathrm{~kg})$ because it will break the materials directly into the M3. However, the observed trend may be due to the breaking strength of the olivine sand particles, which may require more impact (number of drops) to move the material directly from the M1 to the M3. Likewise, the bed mass may also be a contributing factor to the observed trend. To that effect, we decided to go the extra mile to observe the trend while varying the number of drops and bed mass (see Figures 6-9).

Figure 4 shows a typical AR plot of the mass fraction of material in the M3 against the drop heights for the different drop shapes and drop weights. As seen in Figure 4, a gradual increase in the drop height from $0.5 \mathrm{~m}$ to $2.5 \mathrm{~m}$ increases the mass fraction of material in the M3 for all drop weight shapes employed. This figure is consistent with earlier plots (Figures 2 and 3), which indicates that the spherical shape is superior in producing an optimum mass fraction of material within the defined class sizes. If our objective was to maximize the production of materials in the M3, a heavier drop weight $(0.441 \mathrm{~kg})$ could be the appropriate option to use. 


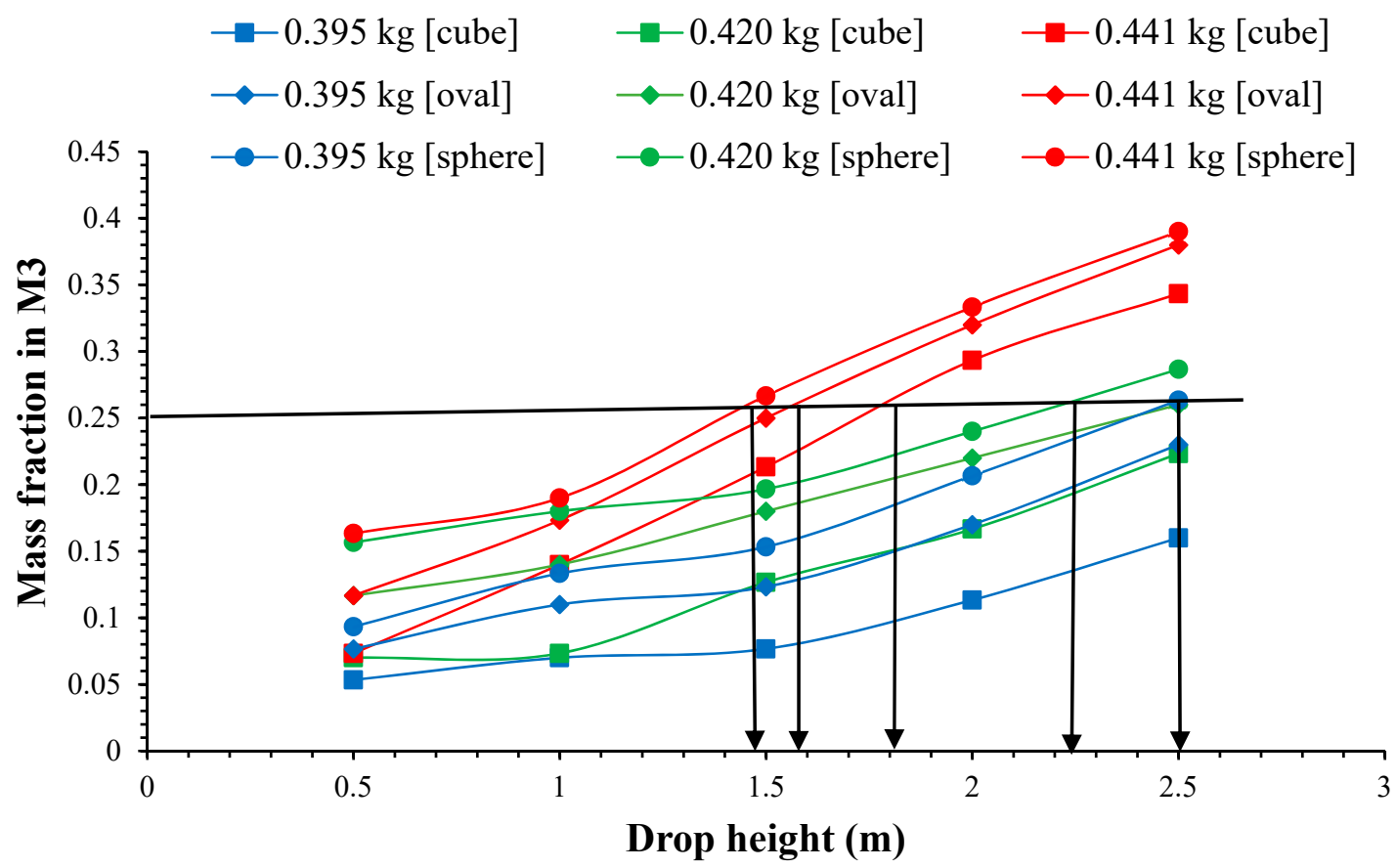

Figure 4. Mass fraction of material in the M3 vs. the drop height for different drop shapes and weights (bed mass $=30 \mathrm{~g}$, number of drops $=100$ ).

Similarly, if we aim to achieve a mass fraction of 0.25 of the M3 material in the product, we can accomplish this by releasing the $0.441 \mathrm{~kg}$ spherical drop weight from a height of $1.43 \mathrm{~m}$, or by dropping the $0.441 \mathrm{~kg}$ oval drop weight from a height of $1.55 \mathrm{~m}$, or by dropping the $0.441 \mathrm{~kg}$ cubic drop weight from a height of $1.79 \mathrm{~m}$, or by dropping the $0.420 \mathrm{~kg}$ spherical drop weight from a height of $2.2 \mathrm{~m}$, or by dropping the $0.420 \mathrm{~kg}$ oval drop weight from a height of $2.5 \mathrm{~m}$, or by dropping the $0.395 \mathrm{~kg}$ spherical drop weight from a height of $2.5 \mathrm{~m}$. The difference in the various drop height options lies in the relative amounts of the M1 and M2 materials associated with accomplishing the desired aim. For energy optimization purposes, the AR plot assists the engineer in deciding to drop from a lower height (e.g., dropping from $1.43 \mathrm{~m}$ rather than $2.5 \mathrm{~m}$ ) in order to accomplish the same desired aim while reducing the operational costs such as fabricating longer hollow cylinders.

As mentioned previously, the AR technique is a global optimization method that has applications in various areas. In this study, we went further by demonstrating the mixing process as another area of implementation of the AR method. Figure 5 depicts the mass fraction of material in the M3 produced when a $0.420 \mathrm{~kg}$ cubic drop weight is released from different heights. It is worth noting that $0.420 \mathrm{~kg}$ cubic drop weight was used just for demonstration; hence any other drop weight shape and weight could have been used. The plot (Figure 5) accounts for both the mass that was broken from the M1 directly into the M3, and hence does not report the M2 and the mass broken from M2 into M3. This is in agreement with the AR technique and the law of conservation of mass, as the sum of the mass fraction of material in the M1, M2, and M3 for a given height of breakage should be equal to one. If we aimed to optimize mass fraction of the M3 material from a drop height of $1.4 \mathrm{~m}$, one could just release the $0.420 \mathrm{~kg}$ cubic drop weight from this height on a bed of olivine particles and obtain an $11.4 \%$ yield of the M3. The alternative would be to take a fraction of the feed material and subject it to breakage by a $0.420 \mathrm{~kg}$ cubic drop weight, released from a height of $2.5 \mathrm{~m}$, and mix this product with the remaining fraction of the feed material. The application of this mixing principle increases the yield of the M3 material from $11.4 \%$ to $13.8 \%$, as depicted in Figure 5. This is another demonstration of the application of the AR technique to identify solutions to problems that are not easily noticed. Hence, the AR technique demonstrates that in certain circumstances, mixing is of utmost importance. 


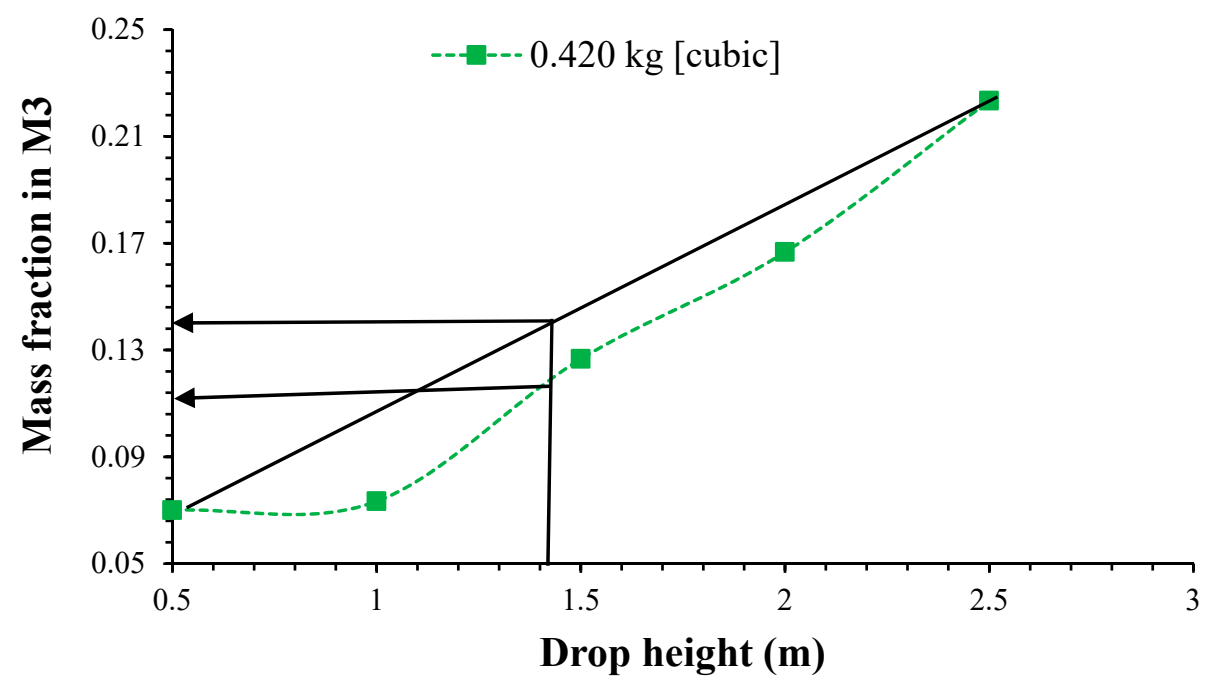

Figure 5. Mass fraction of material in the M3 vs. drop height for a $0.420 \mathrm{~kg}$ cubic drop weight.

Figures 6-8 depict the mass fraction of materials in the M1, M2, and M3 versus the number of drops for the cubic, oval, and spherical drop weights, respectively. As observed in all three figures, the mass fraction of materials in the M1 declines with an increase in the number of drops upon application of all drop weight shapes. This decrease is attributed to the breakage of the materials from the M1 to the M2 and M3. It is also observed from the figures that, for the M2, the mass fraction of material gradually increases with an increase in the number of drops until it reaches a maximum and start declining as the rate at which materials break out of the M2 surpasses the rate at which materials break into the M2 from the M1. It can also be observed from all three figures that materials in the M3 increases gradually with an increase in the number of drops. This increase is attributed to the breakage of materials directly from the M1 to the M3 and from the M1 to M3 via M2.

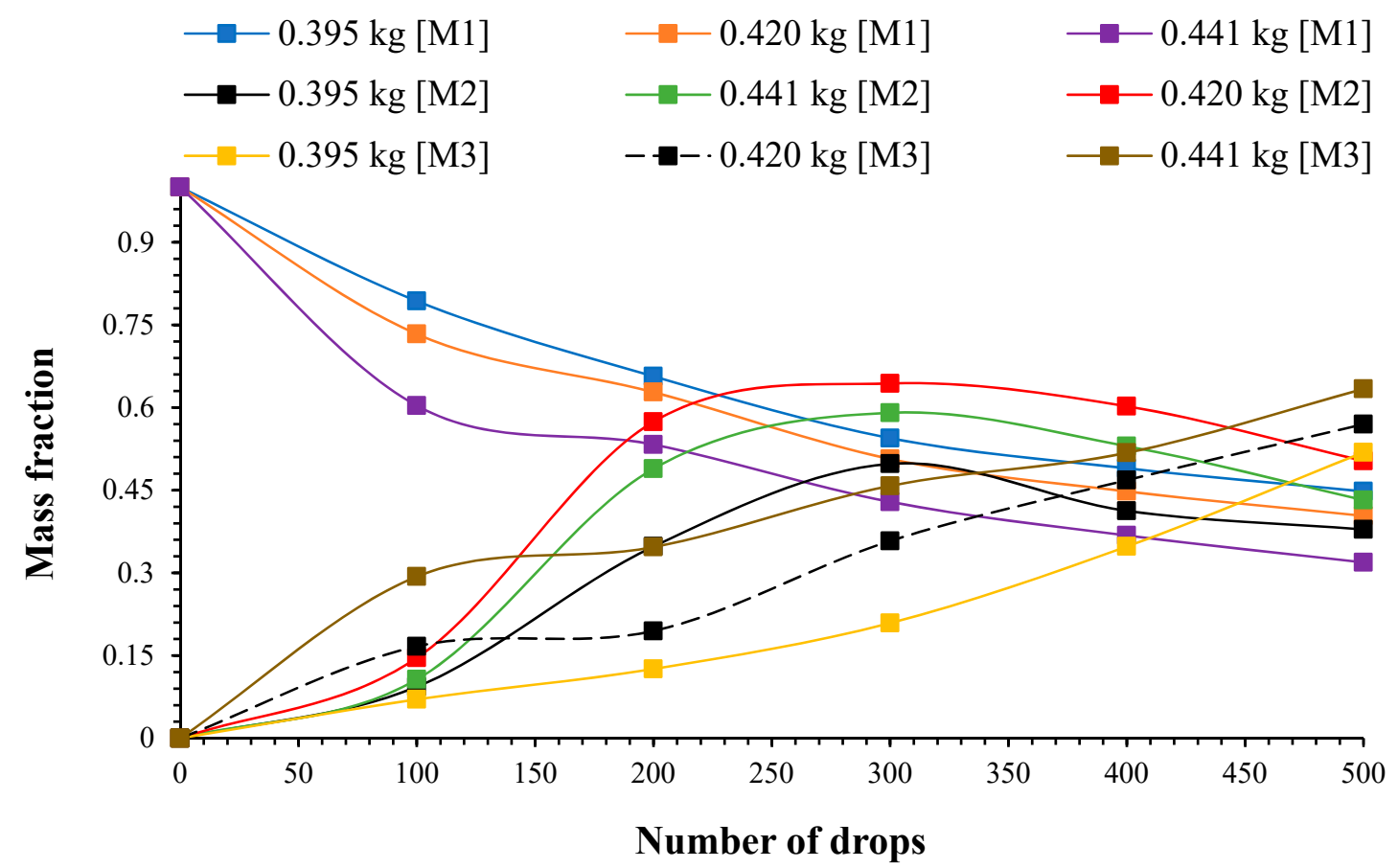

Figure 6. Mass fraction of material (M1, M2, and M3) vs. number of drops for different cubic drop weights (bed mass $=30 \mathrm{~g}$, drop height $=2 \mathrm{~m}$ ). 


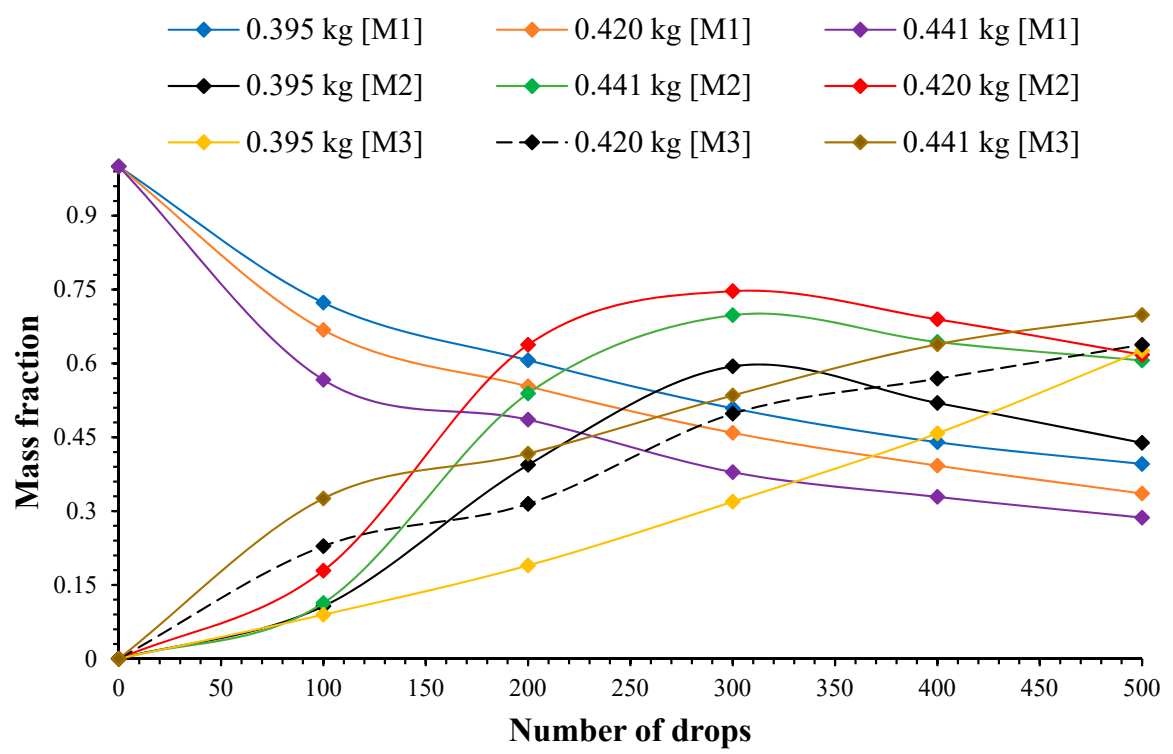

Figure 7. Mass fraction of material (M1, M2, and M3) vs. number of drops for different oval drop weights (bed mass $=30 \mathrm{~g}$, drop height $=2 \mathrm{~m}$ ).

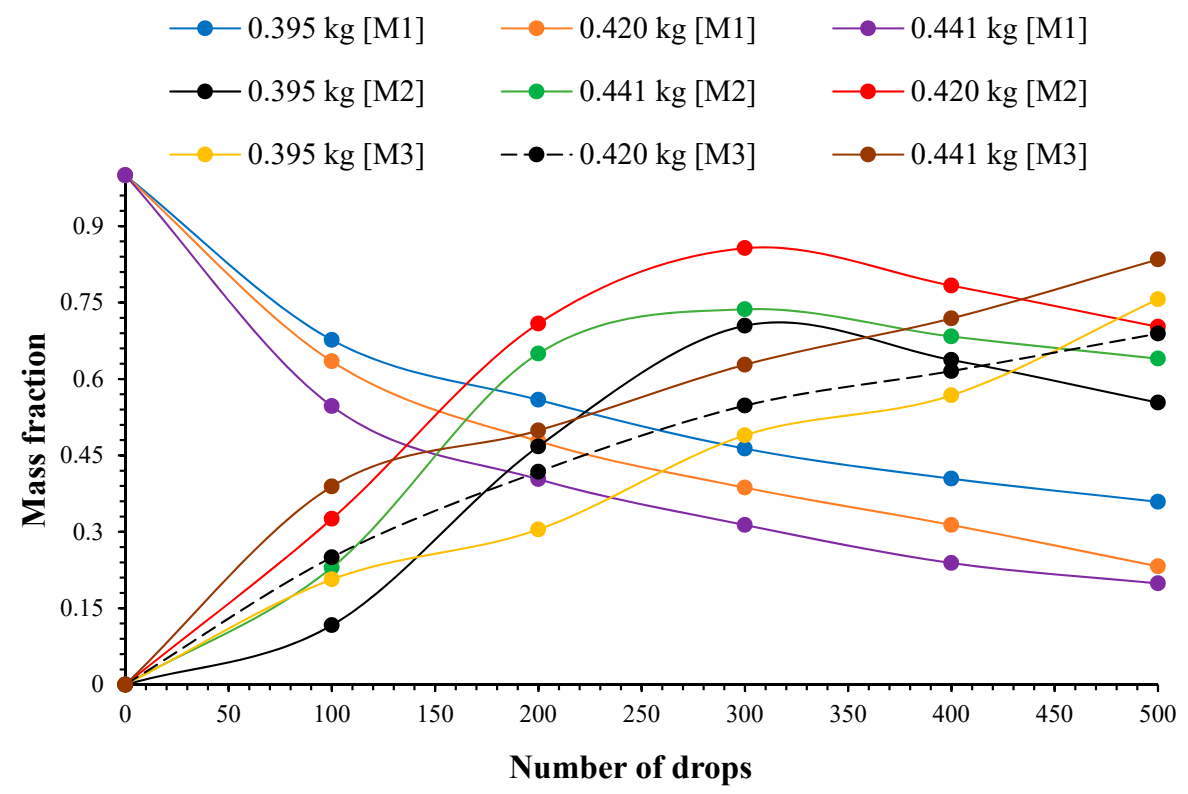

Figure 8. Mass fraction of material (M1, M2, and M3) vs. number of drops for different spherical drop weights (bed mass $=30 \mathrm{~g}$, drop height $=2 \mathrm{~m}$ ).

Comparing all three figures, it can be observed that the spherical drop weight has a higher rate of production of the M2 and M3 and a higher rate of decrease of the M1. The figures also concur with earlier plots (Figures 2-4), which indicates that the spherical drop weight is superior in producing materials in the M2 and M3 and in reducing material in the M1. This superior performance of the spherical drop weight is attributed to its higher surface area and better contact mechanism with the olivine particles.

Figure 9 depicts the AR plot of mass fraction of material in the M1, M2, and M3 upon application of different drop weight shapes versus bed mass. As seen in Figure 9, lower bed mass results in minimum breakage rates for all size classes, owing to loss of energy due to steel (drop weights) to steel (anvil) contacts. Hlabangana et al. [28] indicated that the presence of fewer particles leads to wastage of energy, as the crusher would not be used to its maximum potential. As the bed mass increases, 
an increase in the breakage rate is observed. This increase is attributed to better contact between the drop weights and the olivine particles. As seen in Figure 9, the mass fraction of materials in the M1 size class declines with an increase in the particle bed mass for the different drop weight shapes. It is also observed from Figure 9 that the mass fraction of material in the M2 size class gradually increases with an increase in the particle bed mass until it reaches a maximum and start declining as the rate at which materials break out of the M2 supposes the rate at which materials break into the M2 from the M1 size class. It is also observed from Figure 9 that materials in the M3 size class increase gradually with an increase in the particle bed mass. This increase is attributed to the breakage of materials directly from the M1 to the M3 size class or from the M1 to M2 size class, and finally to the M3 size class. The figure also indicates that at a higher bed mass, low breakage occurs for all drop weight shapes. This low breakage rate at higher bed mass may be attributed to the cushioning effect due to overfilling. Hence, the turning point of the curves for all drop weight shapes gives an optimum amount that can be achieved for the various size classes for a given bed mass.

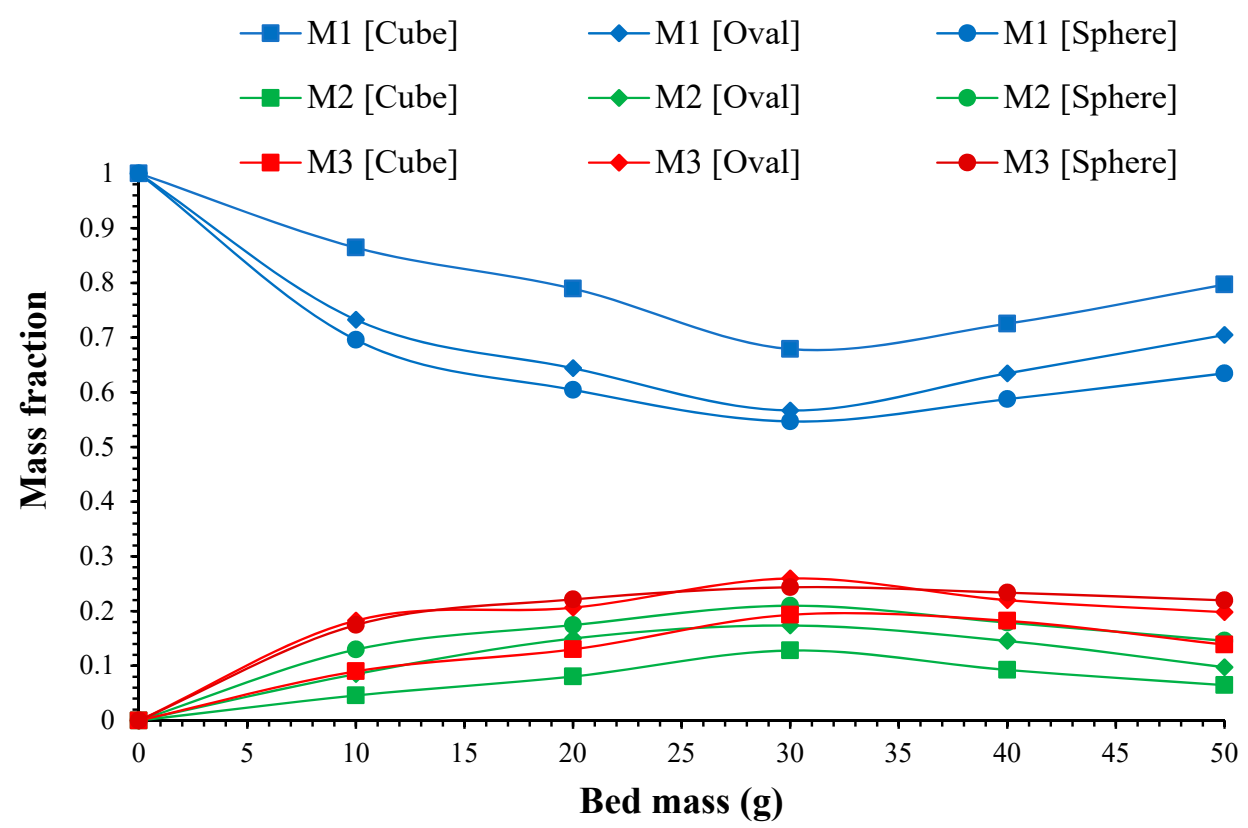

Figure 9. Mass fraction of material (M1, M2, and M3) vs. bed mass for different drop weight shapes (number of drops $=100$, drop weight $=0.441 \mathrm{~kg}$, drop height $=2 \mathrm{~m}$ ).

Figure 10 shows a unique plot, for which we omitted the time dimension to demonstrate the conversion of the M1 size class to the M2 size class. Figure 10 depicts the AR plot of the M2 size class $(-420+75 \mu \mathrm{m})$ versus the M1 size class $(-2000+420 \mu \mathrm{m})$, under various drop weight shapes. For this feed size class, we observed that as the drop weights were varied from $0.395 \mathrm{~kg}$ to $0.441 \mathrm{~kg}$ for the various drop weight shapes, there was an increase in the optimum amount of the M2 size class material, leading one to infer that there is a linear relationship between the drop weight and production of the M2 size class material. For the different drop weight shapes investigated, the spherical drop weight shape was found to give the optimum production of M2 size class material. This phenomenon can be elucidated in terms of the probability of breakage occurring to the desired product output, as discussed earlier. The turning point of the plots in Figure 10 represents an optimum solution, i.e., the maximum amount of the M2 size class produced. Figure 11 is obtained from Figure 10, showing only the $0.441 \mathrm{~kg}$ spherical drop weight case. Figure 11 shows that if our objective is to have $13 \%$ of the product mass in the M2 size class, we can associate it with either $60 \%$ of product material in the M1 size class and 27\% of material in the M3 size class (point A), or with $69 \%$ of the mass in the M1 size class and $18 \%$ of material in the M3 size class (point B), with the aid of mass balances. 


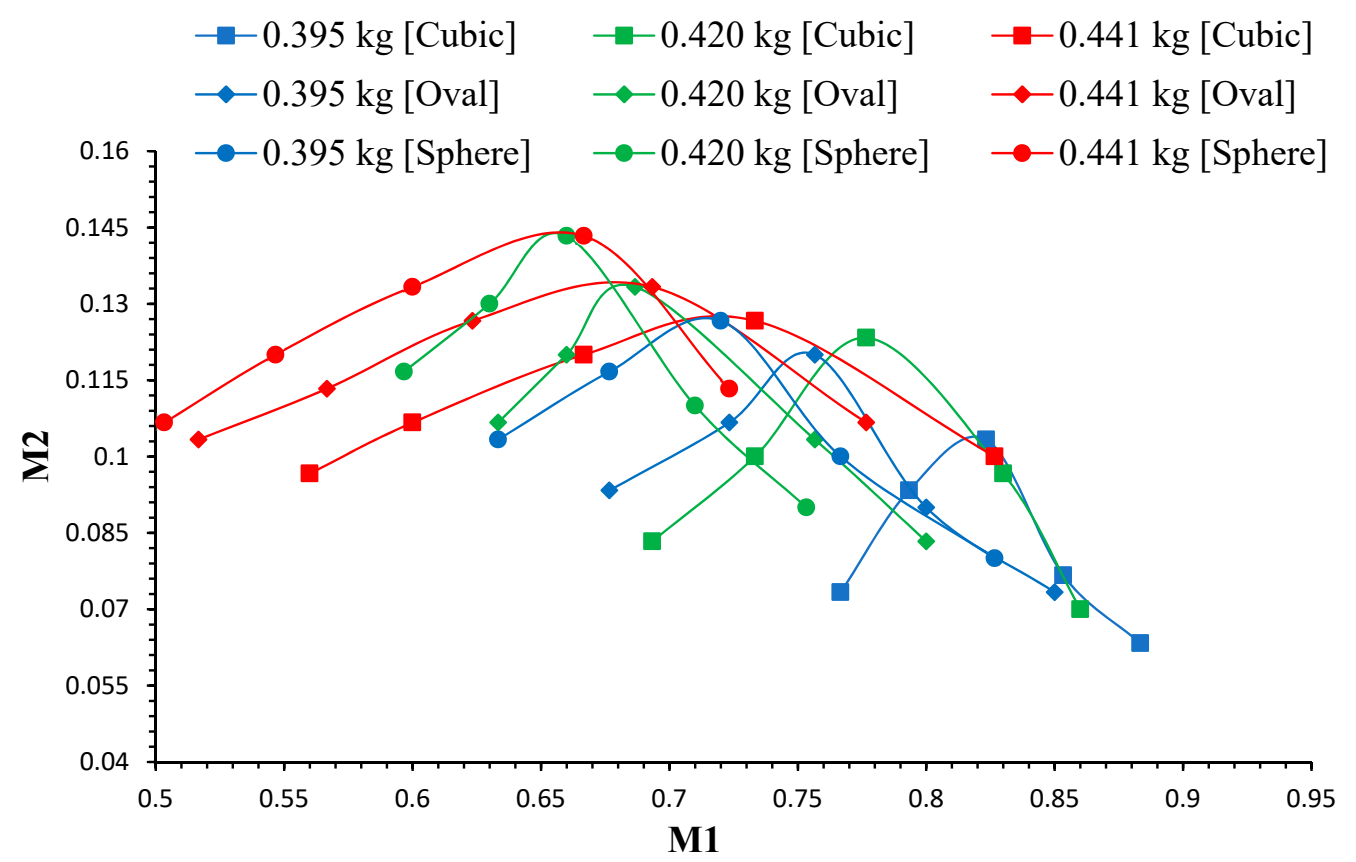

Figure 10. Mass fraction of material in the intermediate size class (M2) versus the mass fraction of material in the feed size class (M1) for different drop weight shapes.

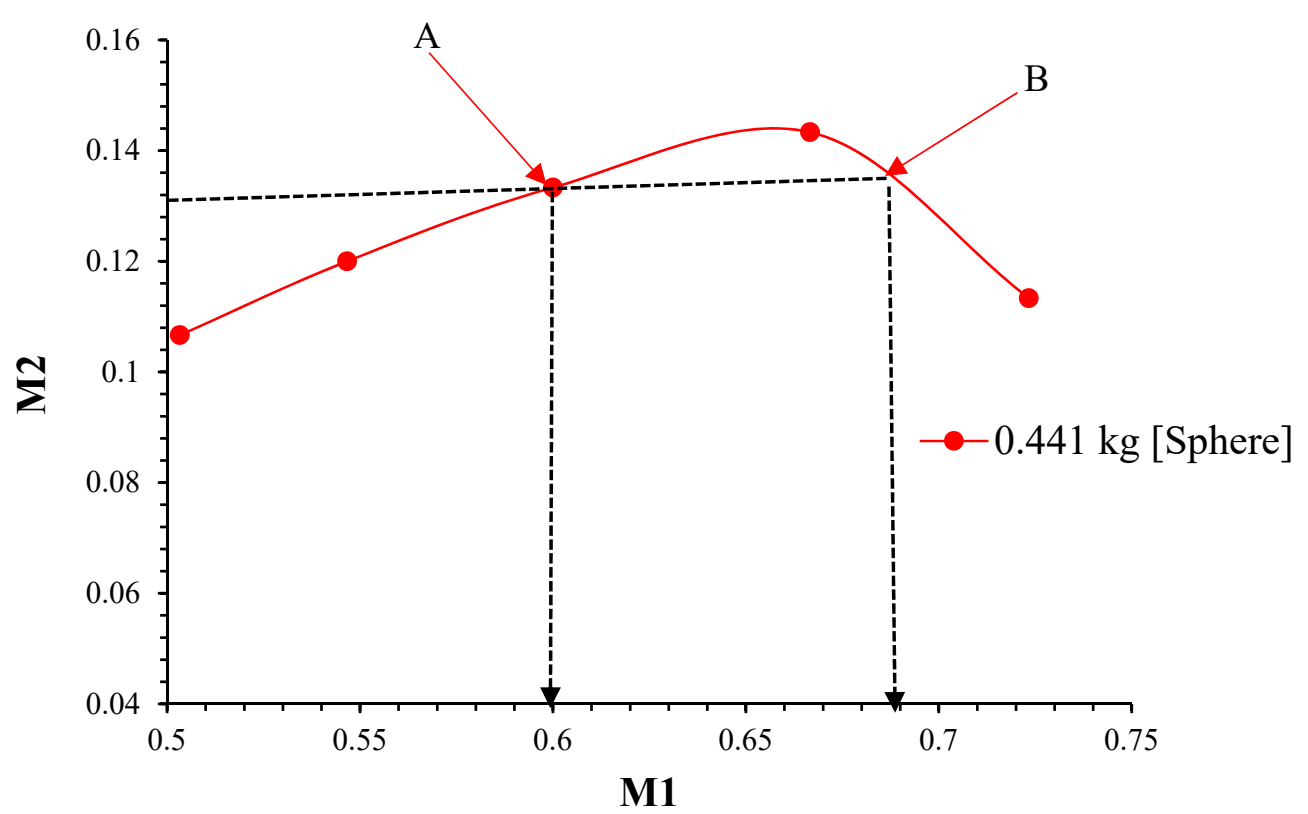

Figure 11. Mass fraction of material in the intermediate size class versus the mass fraction of material in the feed size class for $0.441 \mathrm{~kg}$ spherical drop weight.

Figure 12 shows an AR plot of the M3 size class $(-75 \mu \mathrm{m})$ versus the M1 size class $(-2000+420 \mu \mathrm{m})$ under various drop weight shapes. The region bounded by the plots in Figure 12, $\mathrm{x}$ and $\mathrm{y}$ a-axis, is termed the AR and represents all possible product mass fractions that can be obtained from an initial feed. Figure 12 shows that the production rate of fine size class from the feed material follows an identical trend for all drop weight shapes investigated. A spherical drop weight of $0.441 \mathrm{~kg}$ results in the maximum production of this size class of material. Following the same procedure as that demonstrated in Figure 11, a similar figure can be obtained from Figure 12 upon employing the mixing technique. 


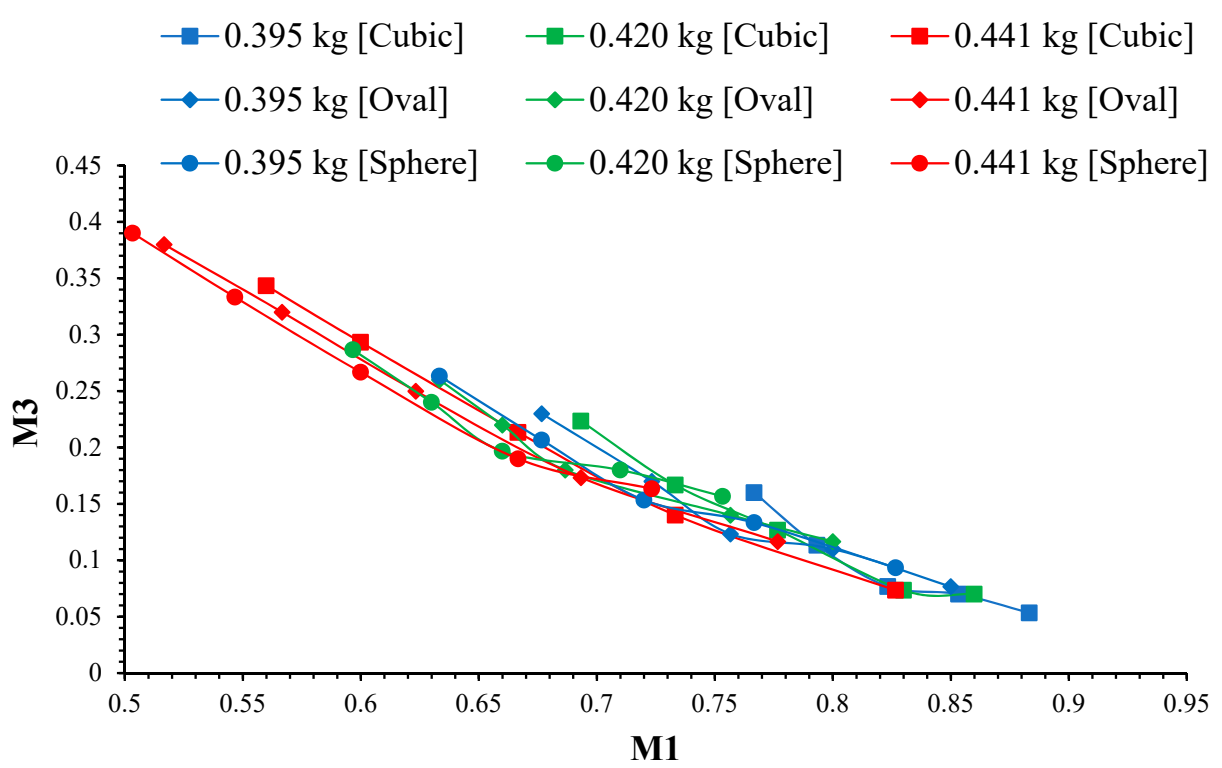

Figure 12. Mass fraction of material in the fine size class (M3) versus the mass fraction of material in the feed size class (M1) for different drop weight shapes.

Figures 13 and 14 depict the relationship between the mass fraction of material in the M1 and the total impact energy, as well as the mass fraction of material in the M3 and the total impact energy, respectively, resulting from releasing the different drop weights from different heights. As seen in Figure 13, an increase in impact energy results in a decrease in the mass fraction of material in the M1. This decrease is due to the breakage of materials from the M1 to the M2 and M3. This finding demonstrates that the amount of energy applied to a material during the comminution process determines the size distribution of the products. Hence, the impact energy is an essential factor to be considered when optimizing olivine particle size during comminution using a drop-weight impact test.

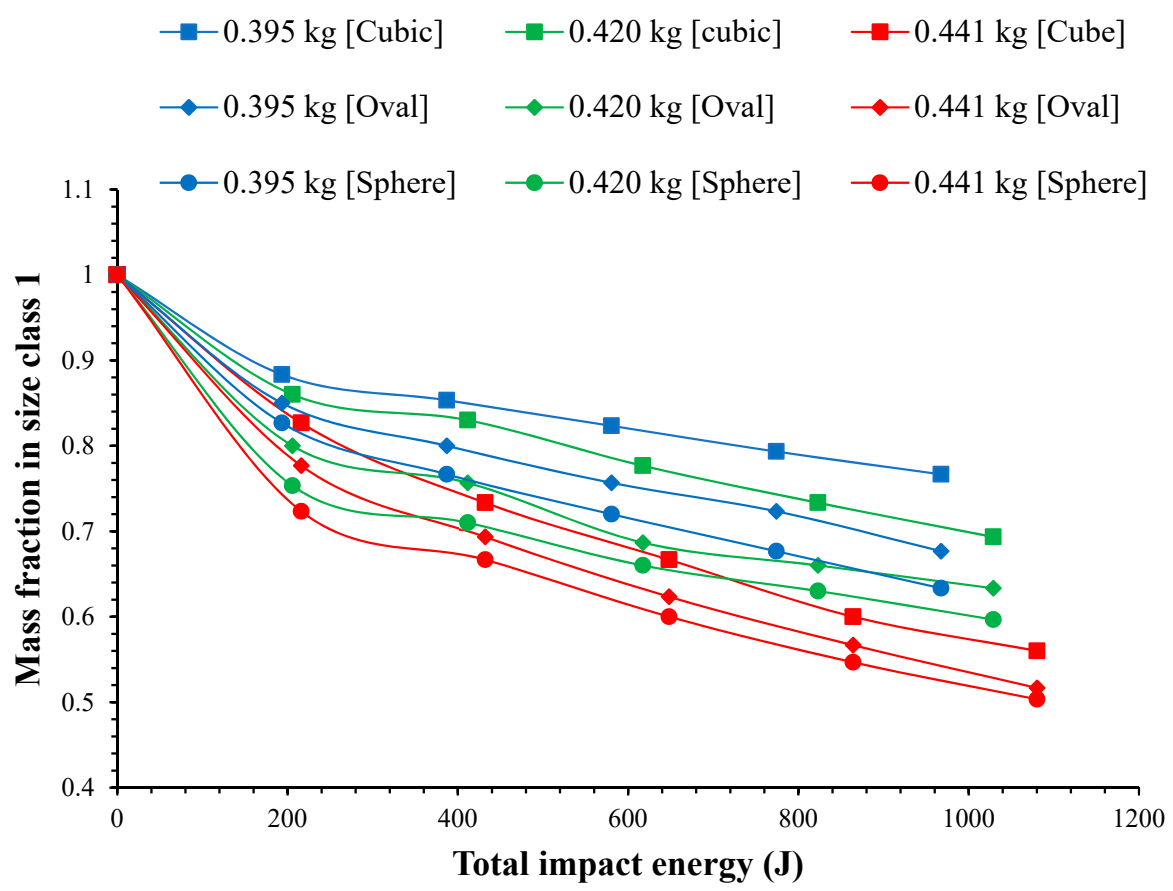

Figure 13. Mass fraction in the M1 vs. total impact energy for the different drop weights and shapes. 


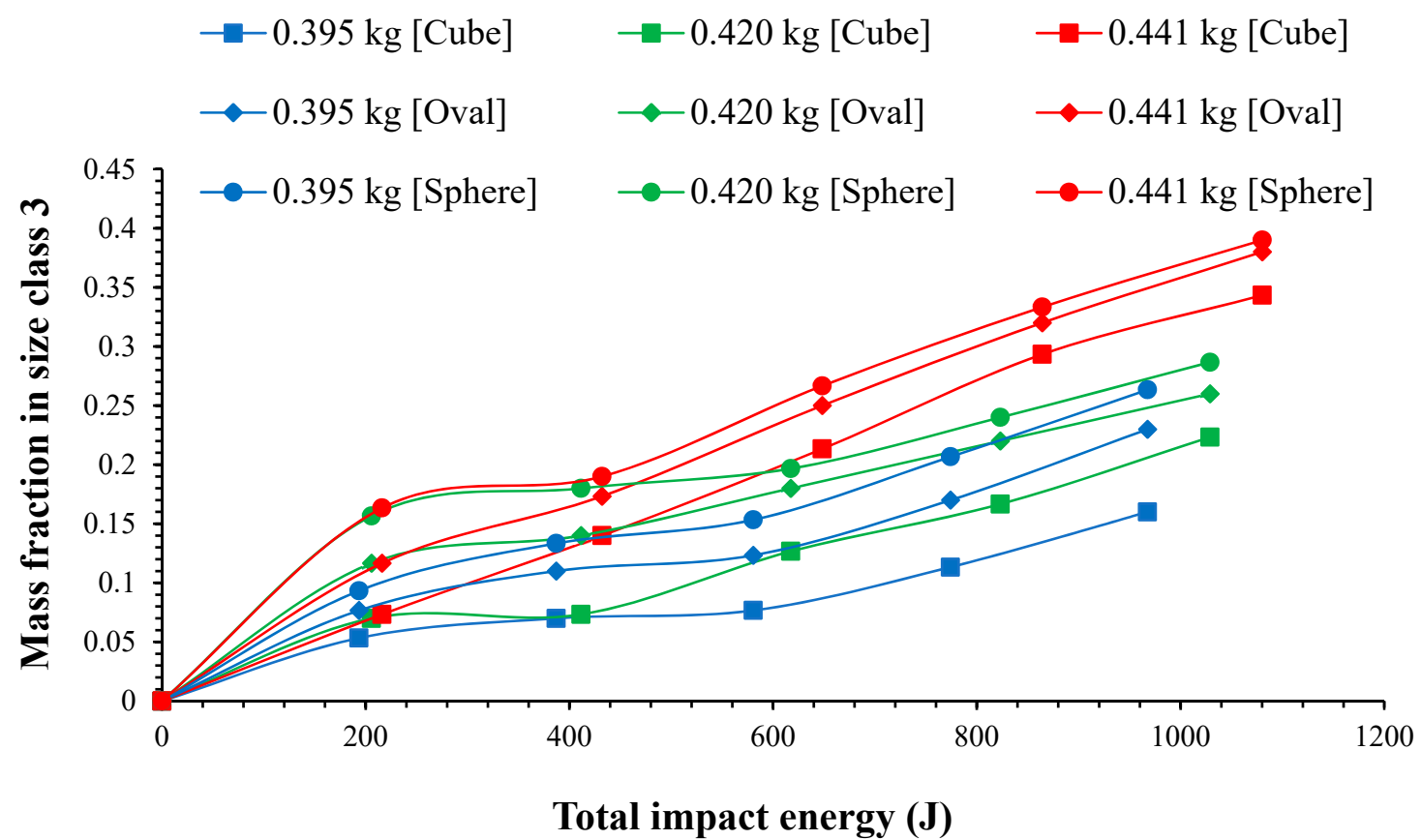

Figure 14. Mass fraction in the M3 vs. total impact energy for the different drop weights and shapes.

Figure 14 demonstrates that as the impact energy increases, the mass fraction of the material in the M3 also increases. This is due to the breakage of materials from both the M1 and M2. Not surprisingly, we can also observe from Figure 14 that heavier drop weight produces finer particles relative to lighter drop weights. Additionally, finer particles were generated when a spherical drop weight was applied compared to when the oval or cubic drop weights were used. This plot complements the earlier plot (Figure 4), which reveals that the spherical drop weight is superior in producing a maximum mass fraction of material in the M3. This finding is of paramount importance, especially when targeting finer olivine particles as additives for sustainable soil stabilization projects.

\section{Conclusions and Future Outlook}

The drop weight impact test was used in the current study to assess the breakage behavior of a bed of olivine sand particles. The AR technique was employed to optimize the impact energy and particle size during the breakage process. This study is one of the first attempts to thoroughly examine the breakage behavior of olivine particles with a perspective for use as an additive in sustainable soil stabilization projects. The authors would like to reiterate that there are no widely accepted ideal comminution product size distributions for olivine particles for use in soil stabilization projects. However, since the reactivity between olivine and the soil increases with a decrease in olivine particle size, we propose that a fine size class of $-75 \mu \mathrm{m}$ could be an ideal comminution olivine product size distribution for use in sustainable soil stabilization projects. The findings demonstrate that the spherical and oval drop weights produced slightly higher materials in the M3 relative to the cubic drop weight. Moreover, the finer size products could be produced in a shorter time (fewer drops) using the spherical and oval drop weights relative to when using the cubic drop weight. This may be due to a better contact mechanism and a higher surface area of the spherical and oval drop weights. Hence, there exists an optimum impact energy (linked to the number of drops) that needs to be reached before breakage can occur. Likewise, there also exists an optimum impact energy that needs to be applied to prevent the material from experiencing over- or under-breakage.

The findings revealed that the required product fineness is a function of the drop height, drop weight, and shape, as well as the feed material size. A higher mass fraction of the fine size class $(-75 \mu \mathrm{m})$ was obtained from the use of a spherical drop weight of $0.441 \mathrm{~kg}$ upon application on a $30 \mathrm{~g}$ 
olivine bed mass from a height of $2.5 \mathrm{~m}$. Hence, the fine size class is ideal for application in soil stabilization due to a better reactivity between the olivine and the soil. It was also observed that, if the objective is to optimize mass fraction of the fine size class (M3) material from a drop height of $1.4 \mathrm{~m}$, the application of the mixing principle increases yield of mass fraction of the M3 from $11.4 \%$ to $13.8 \%$. This finding has significant implications for obtaining the required fine size of olivine particles for sustainable soil stabilization projects, since the reactivity between the soil and olivine increases with the fineness of the olivine particles.

Summarily, the attainable region technique has proven to be a practical approach to optimize the impact energy and particle size during the breakage of a bed of olivine particles using a drop-weight impact test. The findings reported here shed new light when considering olivine as an additive for sustainable soil stabilization projects. Likewise, the significance of this study is geared towards minimizing the inefficiency of the crushing process as optimized impact energy and product size is achieved. Finally, the study also opened up a promising perspective for using the attainable region approach in defining the optimal target (i.e., desired particle size class) as well as determining the optimum operating parameters required in achieving the optimal target (i.e., desired impact energy, drop height, drop weight, and drop shape) for olivine comminution. To this end, our research group and similar research groups may be able to employ the optimized operating parameters to get olivine particles in the fine size class $(-75 \mu \mathrm{m})$ as a sustainable soil additive in on-going and future soil stabilization projects. However, it is worth noting that the drop weight impact test may not be suitable for use in large scale grinding purposes. Hence, it would be interesting to assess the breakage of a bed of olivine particles using comminution equipment with the potential of mass production while optimizing the operating parameters. Furthermore, future work should investigate the ability of the AR method to recommend more energy-efficient policies. It would also be of interest to describe the comminution behavior of olivine sand using other techniques like the population balance equations (PBEs). It is also recommended that during sample splitting, other splitting methods like the riffling splitting technique be used. Further work also needs to be carried out using different boundary criteria or class specifications to examine if the behavior observed in our work extends to other size classes. Likewise, it will also make it easier to compare the AR technique with other analytical methods that are used in comminution. Finally, future studies are also recommended on comparing the studied feed material (olivine) Bond Work Index to other conventional materials like coal, slag, silica sand, bottom ash, etc., used for soil stabilization.

Author Contributions: The contributions of each author listed in this manuscript includes: Conceptualization: E.E., V.A., and A.A.; Methodology: E.E.; Investigation: E.E., and V.A.; Formal analysis: E.E., V.A., and A.A.; Validation: E.E.; Visualization: E.E., and V.A.; Data Curation: E.E.; Software: E.E.; and V.A.; Writing-Original Draft: E.E.; Funding acquisition: V.A.; A.S.; and S.C.P.; Project administration: V.A.; and A.A.; Resources: V.A., A.S., S.C.P.; and A.A.; Supervision: V.A., A.S., S.C.P.; and A.A.; Writing-Review \& Editing: V.A., A.S., S.C.P.; and A.A. All authors have read and agreed to the published version of the manuscript.

Funding: This research did not receive any specific grant from funding agencies in the public, commercial, or not-for-profit sectors.

Acknowledgments: The authors express gratitude to the Abunde Sustainable Engineering Group for its valued recommendations.

Conflicts of Interest: The authors declare no conflict of interest.

\section{References}

1. Rudge, J.F.; Kelemen, P.B.; Spiegelman, M. A simple model of reaction-induced cracking applied to serpentinization and carbonation of peridotite. Earth Planet. Sci. Lett. 2010, 291, 215-227. [CrossRef]

2. Yi, Y.; Liska, M.; Unluer, C.; Al-Tabbaa, A. Carbonating magnesia for soil stabilization. Can. Geotech. J. 2013, 50, 899-950. [CrossRef]

3. Cai, G.H.; Du, Y.J.; Liu, S.Y.; Singh, D.N. Physical properties, electrical resistivity, and strength characteristics of carbonated silty soil admixed with reactive magnesia. Can. Geotech. J. 2015, 52, 1699-1713. [CrossRef] 
4. Emmanuel, E.; Anggraini, V.; Asadi, A.; Raghunandan, M.E. Interaction of landfill leachate with olivine-treated marine clay: Suitability for bottom liner application. Environ. Technol. Innov. 2020, 17, 100574. [CrossRef]

5. Emmanuel, E.; Anggraini, V. Effects of desiccation-induced cracking and leachate infiltration on the hydraulic conductivity of natural and olivine-treated marine clay. Int. J. Environ. Sci. Technol. 2019, 17, 2259-2278. [CrossRef]

6. Kelemen, P.B.; Hirth, G. Reaction-Driven cracking during retrograde metamorphism: Olivine hydration and carbonation. Earth Planet. Sci. Lett. 2012, 345-348, 81-89. [CrossRef]

7. Saldi, G.D.; Daval, D.; Morvan, G.; Knauss, K.G. The Role of Fe and redox conditions in olivine carbonation rates: An experimental study of the rate limiting reactions at 90 and $150{ }^{\circ} \mathrm{C}$ in open and closed systems, Geochim. Cosmochim. Acta 2013, 118, 157-183. [CrossRef]

8. Emmanuel, E.; Anggraini, V.; Raghunandan, M.E.; Asadi, A.; Bouazza, A. Improving the engineering properties of a soft marine clay with forsteritic olivine. Eur. J. Environ. Civ. Eng. 2019, 1-28. [CrossRef]

9. O'Connor, K.; William, D.C.; Dahlin, D.N.; Nilsen, G.E.; Rush, R.P.; Walters, P.C.M.; Turner, P.C. Carbon dioxide sequestration by direct mineral carbonation: Results from recent studies and current status. No. DOE/ARC-2001-029. In Proceedings of the Albany Research Center (ARC), Albany, Oregon. 1st Annual DOE Carbon Sequestration Conference, Washington, DC, USA, 1 May 2001.

10. Metzger, M.J.; Desai, S.P.; Glasser, D.; Hildebrandt, D.; Glasser, B.J. Using the attainable region analysis to determine the effect of process parameters on breakage in a ball mill. AIChE J. 2011, 58, 2665-2673. [CrossRef]

11. Danha, G.; Legodi, D.; Hlabangana, N.; Bhondayi, C.; Hildebrandt, D. A fundamental investigation on the breakage of a bed of silica sand particles: An attainable region approach. Powder Technol. 2016, 301, 1208-1212. [CrossRef]

12. Khumalo, N.; Glasser, D.; Hildebrandt, D.; Hausberger, B.; Kauchali, S. The application of the attainable region analysis to comminution. Chem. Eng. Sci. 2006, 61, 5969-5980. [CrossRef]

13. Khumalo, N.; Glasser, D.; Hildebrandt, D.; Hausberger, B. Improving comminution efficiency using classification: An attainable region approach. Powder Technol. 2008, 187, 252-259. [CrossRef]

14. Austin, L.G.; Shoji, K.; Luckie, P.T. The effect of ball size on mill performance. Powder Technol. 1976, 14, 71-79. [CrossRef]

15. Tangsathitkulchai, C.; Austin, L.G. The effect of slurry density on breakage parameters of quartz, coal and copper ore in a laboratory ball mill. Powder Technol. 1985, 42, 287-296. [CrossRef]

16. Austin, L.G. A discussion of equations for the analysis of batch grinding data. Powder Technol. 1999, 106, 71-77. [CrossRef]

17. Dong, H.; Moys, M.H. Load behavior and mill power. Int. J. Miner. Process. 2003, 69, 11-28. [CrossRef]

18. Kiangi, K.K.; Moys, M.H. Particle filling and size effects on the ball load behaviour and power in a dry pilot mill: Experimental study. Powder Technol. 2008, 187, 79-87. [CrossRef]

19. Yildirim, K.; Cho, H.; Austin, L.G. The modeling of dry grinding of quartz in tumbling media mills. Powder Technol. 1999, 105, 210-221. [CrossRef]

20. Tangsathitkulchai, C. Effects of slurry concentration and powder filling on the net mill power of a laboratory ball mill. Powder Technol. 2003, 137, 131-138. [CrossRef]

21. Lameck, N.S.; Kiangi, K.K.; Moys, M.H. Effects of grinding media shapes on load behaviour and mill power in a dry ball mill. Miner. Eng. 2006, 19, 1357-1361. [CrossRef]

22. Hlabangana, N.; Danha, G.; Mguni, N.G.; Madiba, M.S.; Bhondayi, C. Determining an optimal interstitial filling condition: An Attainable Region approach. Powder Technol. 2018, 327, 9-16. [CrossRef]

23. Duarte, M.; Suárez, A.; Bassi, D. Control of grinding plants using predictive multivariable neural control. Powder Technol. 2001, 115, 193-206. [CrossRef]

24. Chimwani, N.; Glasser, D.; Hildebrandt, D.; Metzger, M.J.; Mulenga, F.K. Determination of the milling parameters of a platinum group minerals ore to optimize product size distribution for flotation purposes. Miner. Eng. 2013, 43-44, 67-78. [CrossRef]

25. Metzger, M.J.; Glasser, B.J. Simulation of the breakage of bonded agglomerates in a ball mill. Powder Technol. 2013, 237, 286-302. [CrossRef]

26. Danha, G.; Hildebrandt, D.; Glasser, D.; Bhondayi, C. Application of basic process modeling in investigating the breakage behavior of UG2 ore in wet milling. Powder Technol. 2015, 279, 42-48. [CrossRef]

27. Katubilwa, F.M.; Moys, M.H.; Glasser, D.; Hildebrandt, D. An attainable region analysis of the effect of ball size on milling. Powder Technol. 2011, 210, 36-46. [CrossRef] 
28. Hlabangana, N.; Nhira, E.; Masayile, N.; Tembo, P.; Danha, G. A fundamental investigation on the breakage of a bed of PGM ore particles: An attainable region approach, part 2. Powder Technol. 2019, 346, 326-331. [CrossRef]

29. Lynch, A.J.; Whiten, W.J.; Narayanan, S.S. Ball mill models: Their evolution and present status. Advances in mineral processing: A half-century of progress in application of theory to practice. In Proceedings of the Symposium Honoring Nathaniel Arbiter on his 75th Birthday, New Orleans, LA, USA, 3-5 March 1986; pp. 48-66.

30. Tavares, L.; King, R. Single-particle fracture under impact loading. Int. J. Miner. Process. 1998, 54, 1-28. [CrossRef]

31. Bitra, V.S.P.; Womac, A.R.; Chevanan, N.; Miu, P.I.; Igathinathane, C.; Sokhansanj, S.; Smith, D.R. Direct mechanical energy measures of hammer mill comminution of switchgrass, wheat straw, and corn stover and analysis of their particle size distributions. Powder Technol. 2009, 193, 32-45. [CrossRef]

32. Liu, L.; Kafui, K.D.; Thornton, C. Impact breakage of spherical, cuboidal and cylindrical agglomerates. Powder Technol. 2010, 199, 189-196. [CrossRef]

33. Metzger, M.J.; Glasser, B.J. Numerical investigation of the breakage of bonded agglomerates during impact. Powder Technol. 2012, 217, 304-314. [CrossRef]

34. Abunde, N.F.; Asiedu, N.Y.; Addo, A.; Morken, J.; Østerhus, S.W.; Seidu, R. Simulation of two-dimensional attainable regions and its application to model digester structures for maximum stability of anaerobic treatment process. Water Res. 2019, 163, 114891. [CrossRef]

35. Ming, D.; Glasser, D.; Hildebrandt, D.; Glasser, B.; Metgzer, M. Attainable Region Theory: An Introduction to Choosing an Optimal Reactor; John Wiley \& Sons, Inc.: Hoboken, NJ, USA, 2016.

36. Ming, D.; Glasser, D.; Hildebrandt, D. Application of attainable region theory to batch reactors. Chem. Eng. Sci. 2013, 99, 203-214. [CrossRef]

37. Asiedu, N.Y.; Hildebrandt, D.; Glasser, D. Batch distillation targets for minimum energy consumption. Ind. Eng. Chem. 2014, 53, 2751-2757. [CrossRef]

38. Nisoli, A.; Malone, M.F.; Doherty, M.F. Attainable regions for reaction with separation. AIChE J. 1997, 43, 374-387. [CrossRef]

39. Muvhiiwa, R.F.; Hildebrandt, D.; Glasser, D.; Matambo, T. Applying the attainable region approach to biogas production. In Proceedings of the AIChE Annual Meeting, University of South Africa, Pretoria, South Africa, 19 November 2014; Volume 11, pp. 16-21.

40. Kauchali, S.; McGregor, C.; Hildebrandt, D. Binary distillation re-visited using the attainable region theory. Comput. Chem. Eng. 2000, 24, 231-237. [CrossRef]

41. Mulenga, F.K.; Chimwani, N. Introduction to the use of the attainable region method in determining the optimal residence time of a ball mill. Int. J. Miner. Process. 2013, 125, 39-50. [CrossRef]

42. Metzger, M.J.; Glasser, D.; Hausberger, B.; Hildebrandt, D.; Glasser, B.J. Use of the attainable region analysis to optimize particle breakage in a ball mill. Chem. Eng. Sci. 2009, 64, 3766-3777. [CrossRef]

43. Chimwani, N.; Mulenga, F.K.; Hildebrandt, D. Ball size distribution for the maximum production of a narrowly-sized mill product. Powder Technol. 2015, 284, 12-18. [CrossRef]

Publisher's Note: MDPI stays neutral with regard to jurisdictional claims in published maps and institutional affiliations.

(C) 2020 by the authors. Licensee MDPI, Basel, Switzerland. This article is an open access article distributed under the terms and conditions of the Creative Commons Attribution (CC BY) license (http://creativecommons.org/licenses/by/4.0/). 